\title{
The development of discrete-address manufacturing planning method
}

\author{
Yuri Polyanskov ${ }^{1}$, Artem Lototsky ${ }^{2}$, and Aleksandr Madanov ${ }^{2, *}$ \\ ${ }^{1}$ ULSU, Competence Center "Aviation Technologies and Aviation Mobility", 432017 Ulyanovsk City, L'va Tolstogo st, h.42, Russian \\ Federation \\ ${ }^{2}$ ULSU, Scientific Research Centre of CALS-technologies, 432017 Ulyanovsk City, L'va Tolstogo st, h.42, Russian Federation
}

\begin{abstract}
The article describes the main stages of building the discrete-address manufacturing planning method. The developed discrete-address method ensures manufacturing of part sets "Just-in-Time" for highvariety manufacturing, using the vector planning in the space of the states of parts in the set.
\end{abstract}

In the context of limited demand for products and underutilization of capacity, the priority consists in "improving the efficiency of machine builders by cutting manufacturing and nonmanufacturing costs".

This statement applies to Russian aircraft builders designed for batch production. The machine builders' development strategy options in the current environment have been examined in detail in [9].

According to the customer-oriented market classification by Gartner Group [6], this type of manufacturing cannot be characterized as job manufacturing, as it is based on a pre-engineered process. It does not fully fit the Make-To-Order category either, since most commonly, orders would contain special requirements providing for variability of the products and relevant changes in the existing package of the engineering design documentation. This type of manufacturing differs from Assembling-To-Order, as due to the shortage of current assets, the enterprises lack current reserves. Therefore, the production cycle envisages the manufacturing of virtually the entire set of parts and sub-assemblies "from scratch". The part replicability of this type of manufacturing depends on the product specification and may vary from a single part up to relatively large batches.

Cutting the output of parts at the stage of manufacturing finished products in the context of the company's unchanged spatial and management structure alters the manufacturing typology. The operation consolidation coefficient $\mathrm{K}_{\mathrm{oc}}$ that pursuant to GOST 3.1121-84 USTD is determined in accordance with formula (1) increases due to the decrease in the denominator.

$$
\mathrm{K}_{\mathrm{oc}}=\frac{\sum_{\mathrm{i}} \mathrm{K}_{\mathrm{opi}}}{\mathrm{K}_{\mathrm{ws}}}
$$

where $K_{\text {opi }}$ is the number of operations performed at the $\mathrm{i}$-th work station within a month; $\mathrm{K}_{\mathrm{ws}}$ is the number of work stations.
Depending on this indicator, if $20 \leq \mathrm{K}_{\mathrm{oc}}<40$, the manufacturing type in question is small-batch manufacturing, if $K_{o c} \geq 40$, then - one-off manufacturing [7].

The need to supply finished piece-products by the deadlines under the contracts sets high requirements to the key components of the operations management system: day-to-day manufacturing planning and dispatching. Along with the manufacturing quality, the tasks of managing the parts and sub-assemblies material flow (that increases in size as it approaches the main assembly shop) take center stage.

This type of manufacturing represents a multi-level pyramid with the assembly of the item to be supplied at the top and with the manufacturing of individual parts at the bottom. The intermediate levels comprise the assembly of sub-assemblies that increase in size, transform in units, sub-systems and systems of the finished product as they move upwards. Meanwhile, as the material increases in size, the number of components goes down. All the discrete components of the said flow have a designated purpose in accordance with the specifications and are to be supplied to the next hierarchical level "Just-In-Time" manufacturing system in order to cut the production costs

The balance of the production load in this context is ensured either through the key orders or through cooperation. All the material flows and the components thereof in this order and work system need to be identified.

Therefore, individual parts and sub-assemblies made to their orders have a specific purpose, "Just-In-Time" delivery address. Their manufacturing cycles are to be integrated into the overall order cycle so that they were synchronized in time with the works at the higher hierarchical levels of the assembly.

This type of discrete-address manufacturing is significantly different from conventional discrete MakeTo-Stock manufacturing. Moreover, the supply of the same parts Made-To-Stock as spare parts for the same

\footnotetext{
${ }^{*}$ Corresponding author: madanov.alexandr@yandex.ru
} 
finished product does not represent discrete-address manufacturing, as it has no specific address or dates of application, even though in case of repair works, if there is a demand for specific parts unavailable in the spare-part kit, such parts will be manufactured under the discreteaddress cycle.

It is commonly assumed that the issues of current calendar planning (CCP) of job machine building are poorly formalizable and represent the most challenging domain of manufacturing planning $[1,7,8]$. The methods and quality of CCP for specific manufacturing depend on the planning unit, on the criteria used to estimate the manufacturing launch time of the said unit and on the arrangements for the method of its flow along the manufacturing route $[1,7]$.

The basic unit of discrete manufacturing flow is the part. Let's examine the manufacturing process of an abstract part $D_{j}$, where D stands for its name, and $\mathrm{j}$ - for its address.

Assume that the said part is provided with the complete package of engineering design documentation, including the route sheet. Let's assume that the manufacturing route of part $D_{j}$ comprises a finite set $m$ of process operations.

Note that the only nonrenewable and unrecoverable manufacturing resource is time, and therefore, the part manufacturing process by definition is a dynamic process evolving in time. Time is the independent variable, the argument of any manufacturing process that may quite naturally be taken as the $\mathrm{X}$-axis of the manufacturing chart.

Note that not all scholars treat time as a manufacturing resource. Thus, in some recent studies of manufacturing planning, e.g. in [2], the list of resources includes "capital, manpower, materials (raw supplies), power, tools, machine-tools, information, knowledge". The other sources on the day-to-day management of flexible manufacturing systems [3] view resources as "operation material aids (machine-tools, tools, appliances, lubricating fluids, etc.), power and communications". Time is viewed as the duration of the planning period representing the time limit for accomplishing the end". In the textbook on machine building engineering and day-today management [7], the resources are conceptualized as tangible components of manufacturing - the means and objects of manufacturing, while time "serves as the measure of labor input per unit and as the time period required to manufacture it. In the first instance, time defines the performance level, while in the second - the rate of converting resources into products".

If we treat time as a nonrenewable resource, we can determine its value proceeding from a unidimensional time model of the manufacturing process to a twodimensional, cost-time model of the process enabling us to examine manufacturing costs as a dynamic process, as a function of time.

Let's illustrate the above considerations by developing an ideal discrete-address manufacturing model. The salience of developing an ideal model has been emphasized in [7], as the ideal manufacturing process "provides for the minimization of space and time consumption for the conversion of source materials into the necessary products. Therefore, the principles of managing the ideal process turn into the principles (rules) of saving time and space at the engineering stage".

Generally, the duration of the manufacturing cycle for the parts of one-off (small-batch) production $\mathrm{T}_{\mathrm{mc}}$ may be calculated using formula (2) [7]:

$$
\mathrm{T}_{\mathrm{mc}}=\sum_{i=1}^{\mathrm{m}} \frac{t_{\mathrm{pc} i}}{\mathrm{~K}_{\mathrm{op} i}}+\sum_{i=1}^{\mathrm{m}-1} \frac{t_{i o i}}{\mathrm{~K}_{\mathrm{op} i}}+\sum_{i=1}^{\mathrm{K}_{o p}} t_{\mathrm{n} i},
$$

where: $\quad t_{\mathrm{pc} i}-$ piece-calculation duration of the $i$-th operation; $\mathrm{K}_{\mathrm{op} i}-i$-th operation rate, hereinafter assumed to be equal to $1\left(\mathrm{~K}_{\mathrm{op} i}=1\right)$; $\mathrm{t}_{\mathrm{i} o i}$ - the duration of the interoperation period between $(\mathrm{i}-1)$ and the i-th operations composed of the interoperation waiting time and the interoperation queue time; $t_{n i}$ - the natural holding time at the $i$-th operation.

The manufacturing process of part $\mathrm{D}$ (we will omit index $\mathrm{j}$ at this point, as only one part is examined so far) may be treated as a sequential flow of process operations in time $\mathrm{i}=\{0,1, \ldots, \mathrm{m}\}$ converting the state of the part from the blank part $\left(D_{0}\right)$ to the finished part $\left(D_{m}\right)$. Therefore, throughout the manufacturing process, part $\mathrm{D}$, undergoing changes, consecutively transits $\mathrm{k}$ states, $\mathrm{k}=$ $\{0,1, \ldots, \mathrm{m}\}$, resulting from the $\mathrm{i}$-th process operation immediately preceding each consecutive process operation. Assume that the state of the part during the i-th operation remains unchanged and corresponds to state $D_{k-1}$.

Each i-th operation coincides with the time period for the relevant operation $\left(\tau_{i}\right)$ specified in the manufacturing route. In case of ideal process, $\tau_{\mathrm{i}}=t_{\mathrm{pci}}$. times $\tau_{\mathrm{i}}$ vary for different operations. Taking the manufacturing launch time of the part for the benchmark, i.e. assuming $\mathrm{t}_{0}=0$, the transition of the part into state $\mathrm{k}$ at discrete time $\mathrm{t}_{\mathrm{k}}$ will be defined by the sum of preceding operations times $\tau_{\mathrm{i}}$, i.e.

$$
\mathrm{t}_{\mathrm{K}}=\sum_{\mathrm{i}=0}^{\mathrm{k}} \tau_{\mathrm{i}}=\mathrm{t}_{\mathrm{k}-1}+\tau_{\mathrm{i}}, \text { where } \mathrm{k}=0,1, \ldots \mathrm{m} .
$$

Time $t_{D}=t_{m}=\sum_{i=0}^{m} \tau_{i}-$ is the full manufacturing time of the part. Note that this is the minimum time for manufacturing the part strictly subject to the manufacturing route. The issue concerning the potential optimization of the manufacturing route is not examined here. The relocation time of the part, e.g. relocation of the part between the shops, should it be significant, may also be included in the manufacturing route as the relevant i-th operation changing the location of the part, which we will equally treat as state transition from state $D_{i-1}$ to $D_{i}$. Therefore, the time axis $t$ breaks down into $\mathrm{m}$ unequal intervals as depicted in Fig. 1.

Let's turn to the Y-axis, since the part state transition function that we will refer to as the manufacturing function (not to be confused with the production function in microeconomics). As over the course of manufacturing, part $\mathrm{D}$ undergoes multiple states $\left\{\mathrm{D}_{0}, \mathrm{D}_{1}, \ldots, \mathrm{D}_{\mathrm{k}}, \ldots \mathrm{D}_{\mathrm{m}}\right\}$ from the blank part $D_{0}$ to the finished part $D_{m}$, the percentage of completion of the part along the manufacturing route changes from $0 \%$ (blank part $\mathrm{D}_{0}$ ) to $100 \%$ (finished part $\mathrm{D}_{\mathrm{m}}$ ). Therefore, we can introduce the availability function $g_{k}$ that, corresponding to the part states $D_{k}$, will naturally reflect the manufacturing process. The completion function $\mathrm{g}_{\mathrm{k}}(\mathrm{t})$ introduced this way has 
certain weaknesses, specifically, it fails to provide us with the Y-axis creation algorithm, i.e. with the procedure for the quantitative breakdown of the section $[0 \%, 100 \%]$ into $\mathrm{m}$ intervals corresponding to the percentages of part completion between two adjacent states $\mathrm{D}_{\mathrm{k}-1}$ and $\mathrm{D}_{\mathrm{k}}$.

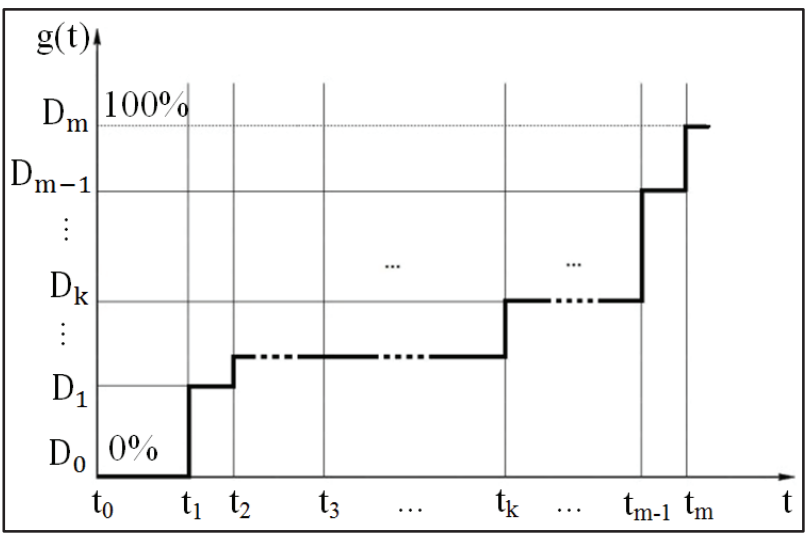

Fig. 1. State transitions of the part during the manufacturing process.

To fill in these gaps, let's use the cost approach. As the part is being manufactured, the enterprise invests its resources that raise the cost of the part from the cost of the blank part $\mathrm{D}_{0}$ to the cost of the finished part $\mathrm{D}_{\mathrm{m}}$. These costs may be expressed through the cost of a conventional standard hour $\psi_{i}$ of the $i$-th process operation measured as $\mathrm{Rub} / \mathrm{h}$. Generally, process operations may be performed at a variety of manufacturing areas in a variety of shops (e.g. post-machining application of galvanic coating). Moreover, these may comprise the intershop logistics operations or natural holding processes included in the route sheet. Therefore, in a general case, variation in the standardized resource intensity of operations should be considered that is defined through the cost of the i-th conventional standard hour $\psi_{i}=$ var.

Therefore, apart from the dataset for the time of manufacturing operations $\left\{\tau_{i}, i=0,1, \ldots, m\right\}$, the task of developing the manufacturing model requires data on the cost of the relevant conventional standard hour, i.e. a dataset for the standardized cost of the relevant operations $\left\{\psi_{i}, \mathrm{i}=0,1, \ldots, \mathrm{m}\right\}$.

The cost of the i-th manufacturing operation vi is calculated according to formula (4)

$$
v_{\mathrm{i}}=\psi_{\mathrm{i}} \cdot \tau_{\mathrm{i}}
$$

The current manufacturing cost of the part in the k-th state is determined as

$$
\mathrm{p}_{\mathrm{K}}=\sum_{\mathrm{i}=0}^{\mathrm{k}} v_{\mathrm{i}}=\sum_{i=0}^{k}\left(\Psi_{i} \cdot \tau_{\mathrm{i}}\right)
$$

Therefore, the source data for developing the model of part $\mathrm{D}$ manufacturing process is matrix $\mathrm{TD}=$ $\left\{\begin{array}{l}\tau_{i}, \\ \psi_{i},\end{array}, i=0,1, \ldots m\right\}$. Use equations (3) and (5) to obtain the part manufacturing matrix from matrix TD:

$$
\mathrm{PD}=\left\{\begin{array}{c}
t_{k}, \\
\left.p_{k}\left(t_{k}\right), k=0,1, \ldots m\right\} .
\end{array}\right.
$$

In matrix $\mathrm{PD}$, the time function $p_{k}\left(t_{k}\right)$, is the step function of time with discontinuity of the first kind.
Matching each state of the part $\mathrm{D}_{\mathrm{k}}$ to the relevant dot on the plane $(\mathrm{p}, \mathrm{t}) \mathrm{D}_{\mathrm{k}} \leftrightarrow\left(p_{k}, t_{k}\right)$ and connecting these dots in the form of a piecewise broken line $\mathrm{w}(\mathrm{t})$ as provided on Fig. 2, we get the part manufacturing trajectory in monetary terms. Therefore, function $\mathrm{p}_{\mathrm{k}}\left(\mathrm{t}_{\mathrm{k}}\right)$ has the meaning of the part manufacturing function.

Putting a straight line through the dots $\left(p_{0}, t_{0}\right)$ and $\left(p_{m}, t_{m}\right)$, corresponding to the initial and the final (finished) state of the part will produce the linear model of part manufacturing:

$$
\mathrm{v}(\mathrm{t})=\psi_{\mathrm{D}} \cdot \mathrm{t},
$$

where the proportionality constant $\psi_{\mathrm{D}}{ }^{\cdot}=\mathrm{p}_{\mathrm{m}} / \mathrm{t}_{\mathrm{m}}$ has the meaning of the cost of the conventional average standard hour for manufacturing part $\mathrm{D}$.

It is obvious that if $\psi_{\mathrm{i}}=\psi=$ const, then formula (7) implies that $\mathrm{p}_{\mathrm{m}}=\psi \cdot \mathrm{t}_{\mathrm{m}}$ and $\psi_{\mathrm{D}}=\psi$. This means that the part manufacturing trajectory will be defined through a linear function - rectangle diagonal (Fig. 2). In case of the large number of operations with the variable cost of the conventional standard hour $\psi_{i}=$ var, a more accurate approximation of $\mathrm{v}(\mathrm{t})$ may require some other methods, e.g. least-square polynomial approximation.

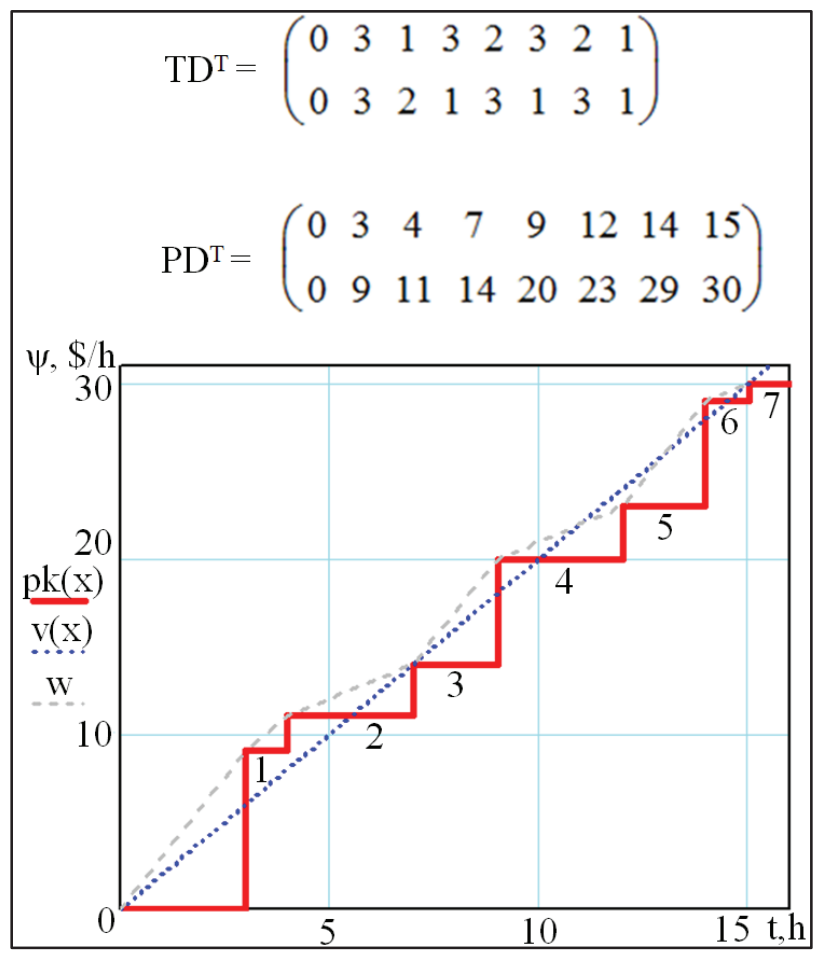

Fig. 2. Part D manufacturing function by the process operations.

Fig. 2 illustrates this through the example of part D manufacturing function based on the transposed process matrix TD, where the first line depicts the times of process operations $\tau_{\mathrm{i}}$ in standard hours, and the second - the cost of the relevant standard hours $\psi_{\mathrm{i}}$, in abstract relative units.

Fig. 2 illustrates the part D manufacturing function by the following process operations: 1 - rough machining, 2 - grinding, 3 - transportation, 4 - chrome plating, 5 transportation, 6 - drilling, 7 - marking.

If we normalize axis $\mathrm{p}$ by $\mathrm{p}_{\mathrm{m}}$, i.e. divide $\mathrm{p}_{\mathrm{k}} / \mathrm{p}_{\mathrm{m}}$, we get the normalized cost scale for manufacturing part $\mathrm{P}_{\mathrm{k}}$ that 
can be expressed in percentage. But previously, we have expressed the completion of part $g_{k}$ in percentage. Therefore, the transformation $\mathrm{g}_{\mathrm{k}}=\mathrm{P}_{\mathrm{k}}=\mathrm{p}_{\mathrm{k}} / \mathrm{p}_{\mathrm{m}}$ has a conceptual meaning assigning the meaning of the relative part manufacturing cost to the part completion concept. Formally, $\mathrm{g}_{\mathrm{k}}$ and $\mathrm{P}_{\mathrm{k}}$ are two different variables, but within the model under consideration, they are isomorphic. Therefore, let's assume that the part relative completion functions $\mathrm{G}(\mathrm{t})$ and functions $\mathrm{g}_{\mathrm{k}}(\mathrm{t})$ and $\mathrm{P}_{\mathrm{k}}(\mathrm{t})$ are identical $\mathrm{G}(\mathrm{t}) \equiv \mathrm{g}_{\mathrm{k}}(\mathrm{t}) \equiv \mathrm{P}_{\mathrm{k}}(\mathrm{t})$.

Similarly, we can move on to the dimensionless normalized scale of the part manufacturing time $\mathrm{T}_{\mathrm{k}}=$ $\mathrm{t}_{\mathrm{k}} / \mathrm{t}_{\mathrm{m}}$.

Fig. 3 depicts the manufacturing function of part D above on the normalized plane.

Therefore, we get a normalized linear model V(T) of part manufacturing, where the part manufacturing optimum trajectory is the unit square diagonal. Meanwhile, function $\mathrm{V}(\mathrm{T})$ represents a linear approximation of the completion function $\mathrm{G}(\mathrm{T})$.

As a matter of convenience, the part manufacturing process may be considered equisignificant either in the rectangle $\left(\mathrm{p}_{\mathrm{m}}, \mathrm{t}_{\mathrm{m}}\right)$ on the plane $(\mathrm{p}, \mathrm{t})$, or in the rectangle $\left(1, \mathrm{t}_{\mathrm{m}}\right)$ on the plane $(\mathrm{G}, \mathrm{t})$ or in the square $(1,1)$ on the normalized plane $(\mathrm{G}, \mathrm{T})$. In the latter case (similarly to the other two), the area beneath line $\mathrm{V}(\mathrm{T})$ or, to be more precise, under the step function $\mathrm{G}(\mathrm{T})$ characterizes the resource intensity of part manufacturing.

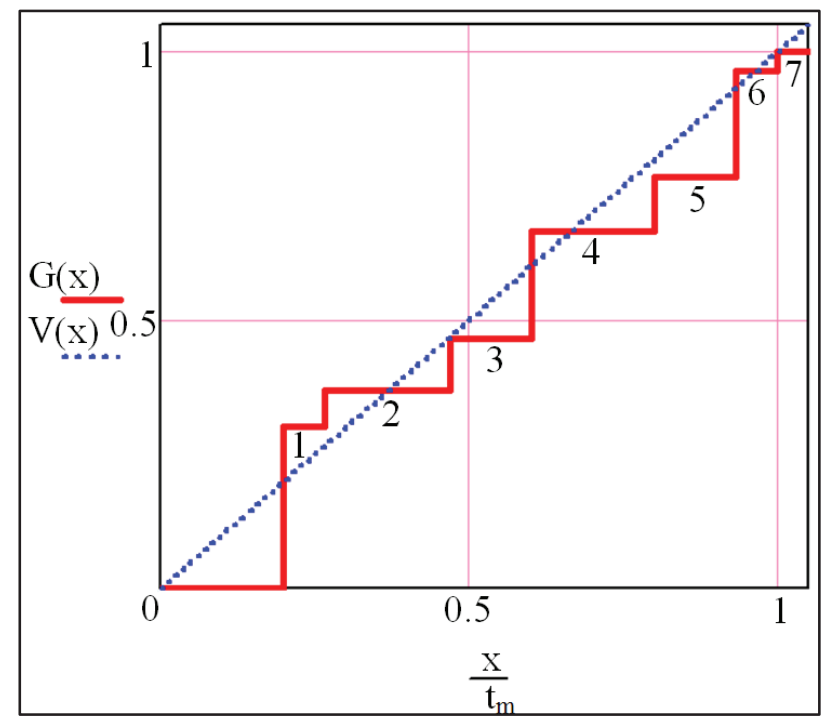

Fig. 3. Part D manufacturing function on the normalized plane.

Deviations from or irregularities of the manufacturing route on the normalized plane $(\mathrm{G}, \mathrm{T})$ may theoretically look like a deviation of the actual manufacturing time of part $\mathrm{T}_{\mathrm{f}}$ from the unit value: $\Delta \mathrm{T}=\mathrm{T}_{\mathrm{f}}-1$. The negative value of $\Delta \mathrm{T}$ (faster than provided in the manufacturing route) either points at the error in the route (we will rule out this possibility by sticking to the previous assumption regarding the completeness and accuracy of the documentation package), or at the irregularities in the process parameters (speed of cutting, duration of chrome plating, etc.). I.e. $\Delta \mathrm{T}$ should be treated as an indirect sign of the worsening quality of the part. The positive value of $\Delta \mathrm{T}$, i.e. delay in manufacturing the part by time $\Delta \mathrm{t}=$
$\Delta \mathrm{T} \cdot \mathrm{t}_{\mathrm{m}}$, apart from direct consequences, also indicates the increase in the actual manufacturing cost of the part by $\Delta p$ $=\psi_{\mathrm{D}} \cdot \Delta \mathrm{t}$.

Let's proceed to the consideration of the planning unit through a set of parts for sub-assembly K. Take the simplest case, where the set consists of two parts $K=\{D 1$, $\mathrm{D} 2\}$, each of them characterized by its own process matrix: TD1 and TD2 respectively. In a general case, these matrices differ from each other, both in terms of content and quantity of process operations $\mathrm{m} 1 \neq \mathrm{m} 2, \tau 1_{\mathrm{i}}$ $\neq \tau 2_{\mathrm{i}}$, and in terms of respective standard hours cost $\psi 1_{\mathrm{i}} \neq$ $\psi 2$.

Creation of the relevant X-axis G1(t) and G2(t) presents no difficulty and is virtually similar to the case with a single part. This is due to the fact that in physical terms, parts D1 and D2 are two physically unrelated items and therefore, the relevant $\mathrm{X}$-axes are orthogonal and turned $90^{\circ}$ away from each other. Accordingly, the normalized planes $(\mathrm{G} 1, \mathrm{~T})$ and $(\mathrm{G} 2, \mathrm{~T})$ are orthogonal and cross along $\mathrm{X}$-axis $\mathrm{T}$. These planes may be brought into coincidence by turning axis $\mathrm{T} 90^{\circ}$.

The task of creating time axis T may be challenging to a certain extent, if the part manufacturing times are unequal $\mathrm{t}_{\mathrm{m} 1} \neq \mathrm{t}_{\mathrm{m} 2}$, i.e. in the majority of real situations. This is due to the fact that the normalization of the common real time axis $\mathrm{t}$ by heterogeneous values $1 / \mathrm{t}_{\mathrm{m} 1}$ and $1 / t_{\mathrm{m} 2}$ results in the emergence of heterogeneous times $\mathrm{T} 1$ and $\mathrm{T} 2$ in the manufacturing model $\mathrm{K}$, which is unacceptable for application. Therefore, the time axis should be normalized by the larger manufacturing time value. Suppose, that $t_{\mathrm{m} 1}>t_{\mathrm{m} 2}$, then axis $t$ should be normalized by $t_{\mathrm{m} 1}$ value. In this case, the square $(\mathrm{G} 2, \mathrm{~T})$ shall become smaller along the $\mathrm{X}$-axis and the relevant width thereof $\mathrm{T}_{\mathrm{m} 2}=\mathrm{t}_{\mathrm{m} 2} / \mathrm{t}_{\mathrm{m} 1}<1$ changes by $\Delta \mathrm{T}_{\mathrm{m}}=\left(\mathrm{t}_{\mathrm{m} 1}-\right.$ $\left.\mathrm{t}_{\mathrm{m} 2}\right) / \mathrm{t}_{\mathrm{m} 1}$.

The manufacturing launch time of the part $\mathrm{t}_{\text {laun }}$ plays an important part in the manufacturing planning practice. The optimum launch time $t_{\text {laun }}^{\text {opt }}$ for a single part is determined so as to minimize the part resource intensity the area beneath line $\mathrm{V}(\mathrm{T})$, and therefore, $t_{\text {laun }}^{\text {opt }}=-\mathrm{t}_{\mathrm{m}}$, where the benchmark $t_{0}=0$ is the launch of the assembly or successive hierarchical level manufacturing. Note that this conclusion is strictly in conformity with the Just-InTime manufacturing strategy.

The same resource intensity minimization principle is universal and applicable to a set of parts. Within a set of parts, the part with the largest $t_{m}$ stands out, the so called core part [7], $\mathrm{t}_{\mathrm{m} 1}$ in the example above. This time determines the so called critical path of the set manufacturing. Manufacturing of the other parts is launched with a time lag against the critical part. The optimum value of this time lag is equal to $\mathrm{t}_{\mathrm{laun}}=\mathrm{t}_{\mathrm{m} 1}-\mathrm{t}_{\mathrm{m} 2}$ $>0$. The same time is the acceptable time lag for the launch of part D2. Bringing the relative planes $(\mathrm{G} 1, \mathrm{~T})$ and $(\mathrm{G} 2, \mathrm{~T})$ in coincidence for the case above subject to $t_{\mathrm{m} 2}=$ $0,5 t_{\mathrm{m} 1}$ is depicted on Fig. 4. The launch times for parts D1 and $\mathrm{D} 2$ are the intersection points of $\mathrm{X}$-axis by lines $\mathrm{V} 1(\mathrm{~T})$ and $\mathrm{V} 2(\mathrm{~T})$, i.e. $\mathrm{T} 1_{\text {laun }}=-1, \mathrm{~T} 2_{\text {laun }}=-0.5$, at axis $\mathrm{T}$ scale equal to $1 / \mathrm{t}_{\mathrm{m} 1}$. 


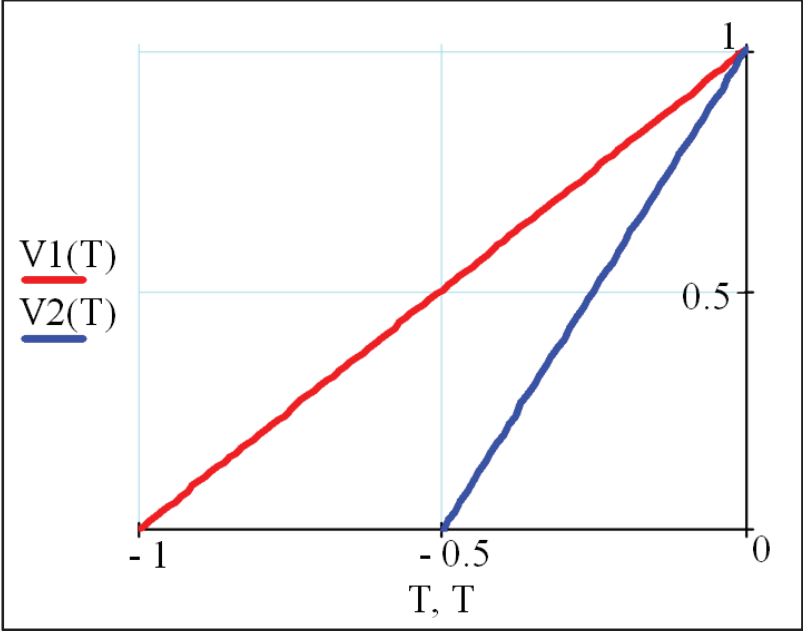

Fig. 4. Bringing relative planes $(\mathrm{G} 1, \mathrm{~T})$ and $(\mathrm{G} 2, \mathrm{~T})$ in coincidence for a two-part set, $\mathrm{t}_{\mathrm{m} 2}=0.5 \mathrm{t}_{\mathrm{m} 1}$

Let's consider the practicality of applying the linear manufacturing model for the set as whole using the example of our model. For illustrative purposes, assume that $\psi_{\mathrm{D} 1}=\psi_{\mathrm{D} 2}$. Then the manufacturing cost of the set will be equal to:

$$
\mathrm{p}_{\mathrm{K}}=\mathrm{p}_{\mathrm{m} 1}+\mathrm{p}_{\mathrm{m} 2}=\psi_{\mathrm{D} 1} \cdot\left(\mathrm{t}_{\mathrm{m} 1}+\mathrm{t}_{\mathrm{m} 2}\right)=1.5 \cdot \mathrm{p}_{\mathrm{m} 1}
$$

The relative cost of the parts in the set will account for $\mathrm{P} 1=\mathrm{p}_{\mathrm{K}} / \mathrm{p}_{\mathrm{m} 1}=0.667, \mathrm{P} 2=\mathrm{p}_{\mathrm{K}} / \mathrm{p}_{\mathrm{m} 2}=0.333$. The resource intensity of set $\mathrm{S}_{\mathrm{Set}}$ linear model is equal to the area beneath the unit square diagonal $\mathrm{S}_{\mathrm{Set}}=0.5$. The resource intensity of the by-part manufacturing model for the set will equal the sum of the areas of the relevant resource intensity triangles for part $\mathrm{D} 1 \mathrm{~S}_{\mathrm{D} 1}=0.333$ and for part D2 $\mathrm{S}_{\mathrm{D} 2}=0.083$, ultimately $-\mathrm{S}_{\mathrm{Sp}}=0.416$. As a result, the linear model produces an inflated resource intensity value ( $20.2 \%$ above the by-part model). The estimation above is depicted on Fig. 5. Therefore, the decision on the practicality of the linear model for set manufacturing should be made individually for each case with consideration of the fact that the resulting value will invariably be inflated.

As modern computing machinery does not impose tight constraints on the computational complexity of manufacturing planning procedures typical for manual methods, it appears practicable to apply the by-part planning model for the manufacturing of sets in the form of parts state matrix composed of the parts state vectors $K_{\mathrm{n}}=\left\{\mathrm{D}_{1}, \mathrm{D}_{2}, \ldots, \mathrm{D}_{\mathrm{j}}, \ldots \mathrm{D}_{\mathrm{n}} ; \mathrm{j}=1, \ldots, \mathrm{n}\right\}$. For practical purposes, it is practicable to present matrix $K_{n}$ in the form of matrix $\mathrm{Kg}_{\mathrm{n}}$ of parts completion vectors $\mathrm{g}_{\mathrm{jk}}$ superimposed on the common discrete axis of state transition time.

An example of such matrix made for a three-part set with $\mathrm{m}_{1}=4, \mathrm{~m}_{2}=3$ and $\mathrm{m}_{3}=4$ transiting through the states at different times is provided on Fig. 6 .

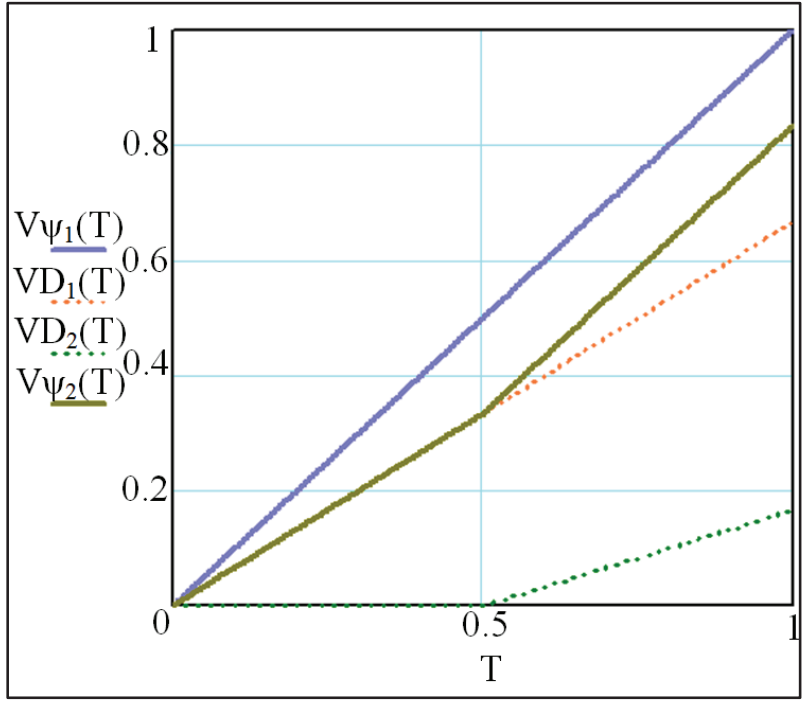

Fig. 5. Linear vs by-part model of set manufacturing.

The number of rows in the matrix equals $n+1=4$, corresponding to the total number of parts plus the common time scale $T_{k}$. The number of columns is equal to the sum of all states, i.e. $\mathrm{m}_{\mathrm{k}}=1+\sum_{j}^{n} m_{j}=12$. If the times when multiple parts transit from one state to another coincide, dimensionality $\mathrm{m}_{\mathrm{k}}$ is automatically reduced by the number of such coincidences. Our matrix has 2 coincidences, as all the parts transit to the end state simultaneously at the last discrete time, which is in conformity with the strategy of the set resource intensity minimization. Hence, the actual dimensionality of matrix $\mathrm{m}_{\mathrm{ka}}=12-2=10$. Columns T4 and T5 may be excluded from the matrix, as the part does not change states at these times (rows are provide for illustrative purposes).

$\mathrm{Kg}=\left(\begin{array}{cccccccccccc}\mathrm{T}_{0} & \mathrm{~T}_{1} & \mathrm{~T}_{2} & \mathrm{~T}_{3} & \mathrm{~T}_{4} & \mathrm{~T}_{5} & \mathrm{~T}_{6} & \mathrm{~T}_{7} & \mathrm{~T}_{8} & \mathrm{~T}_{9} & \mathrm{~T}_{10} & \mathrm{~T}_{11} \\ \mathrm{~g}_{1,0} & \mathrm{~g}_{1,1} & \mathrm{~g}_{1,2} & \mathrm{~g}_{1,2} & \mathrm{~g}_{1,2} & \mathrm{~g}_{1,2} & \mathrm{~g}_{1,3} & \mathrm{~g}_{1,3} & \mathrm{~g}_{1,3} & \mathrm{~g}_{1,3} & \mathrm{~g}_{1,3} & \mathrm{~g}_{1,4} \\ \mathrm{~g}_{2,0} & \mathrm{~g}_{2,0} & \mathrm{~g}_{2,0} & \mathrm{~g}_{2,1} & \mathrm{~g}_{2,1} & \mathrm{~g}_{2,1} & \mathrm{~g}_{2,1} & \mathrm{~g}_{2,1} & \mathrm{~g}_{2,1} & \mathrm{~g}_{2,2} & \mathrm{~g}_{2,2} & \mathrm{~g}_{2,3} \\ \mathrm{~g}_{3,0} & \mathrm{~g}_{3,0} & \mathrm{~g}_{3,0} & \mathrm{~g}_{3,0} & \mathrm{~g}_{3,0} & \mathrm{~g}_{3,0} & \mathrm{~g}_{3,0} & \mathrm{~g}_{3,1} & \mathrm{~g}_{3,2} & \mathrm{~g}_{3,2} & \mathrm{~g}_{3,3} & \mathrm{~g}_{3,4}\end{array}\right)$

Fig. 6. Vector plan matrix

Therefore, the developed discrete-address method ensures manufacturing of part sets "Just-in-Time" for high-variety manufacturing, using the vector planning in the space of the states of parts in the set.

As for the choice between the "pushing" and the "pulling" strategy for the model under consideration, it may be argued that they have different benchmarks: launch time for the pushing strategy and delivery time for the pulling strategy. Meanwhile, the pulling strategy is to operate in the context of "negative time", which is impossible in the absence of current reserves.

The work is performed according to the Russian Federation Program of the Ministry of Education and Science (№2.1816.2017/PCh). 


\section{References}

1. M.I. Bukhalkov, Management Planning - 2nd ed., 400 (INFRA-M, 2003)

2. E. Westcamper, M. Decker, L. Endowby, A.I. Grabchenko, V.L. Dobroskok, Intro into Industrial Engineering, 376 (NTU KPI, 2008)

3. V.F. Gornev, V.V. Emelyanov, M.V. Ovsyannikov, FMS Day-to-Day Management, 256 (Mashinostroenie, 1990)

4. R.R. Zagidullin, Machine-Building Management Using MES, APS, ERP Systems, 372 (TNT, 2011)

5. K.S. Kulga, I.A. Krivosheev, Models and Methods for the Creation of an Integrated IS to Automate Technical Training and Manage Aircraft and Machine Building, 377 (Mashinostroenie, 2011)

6. M. Polyakova, Discrete Manufacturing in Russia, No. 02, (2008)

7. N.S. Sachko, Machine Building Engineering and Day-to-Day Management, 676 (Novoe Znanie, 2005)

8. E.B Frolov., R.R. Zagidullin, MES Systems. TopDown, Inside-Out. The Criteria We Pick (ERPNEWS, 2007)

9. V.N. Tsuglevich, Development Strategy of Russian Machine Builders in the Current Context, 44 (2003) 